\title{
Neonatal Respiratory Therapist-Led Rounds Can Improve Staff Satisfaction and Timeliness of Respiratory Interventions
}

\author{
Irene C Genet RRT, Kimberly S Firestone RRT, and Teresa A Volsko MHHS RRT FAARC
}

\begin{abstract}
BACKGROUND: Interdisciplinary rounding is used to establish and communicate patient care goals and monitor progress toward goal attainment. This study describes staff satisfaction and process outcomes associated with respiratory therapist (RT)-led interdisciplinary rounds in the neonatal ICU. We hypothesized improved staff satisfaction, execution of orders within $30 \mathrm{~min}$ of order entry into the electronic medical record, and communication of accurate and complete data during rounds to the interdisciplinary team. METHODS: Nurses, RTs, nurse practitioners, residents, and attending physicians completed the 13-question survey eliciting demographic information and evaluating staff engagement and professional satisfaction. The survey was anonymous and confidential, and informed consent was implied. Process data were collected for a 10-d period at 2 intervals through direct observation of the rounding process and electronic medical record review. Descriptive statistics reported patient demographics, responses to job satisfaction and engagement survey questions, the number of patients who were visited in daily rounds, the number and type of orders given during rounds, and the number of respiratory orders that were addressed in multidisciplinary teaching rounds rather than during respiratory rounds. The chi-square test was used to determine differences in the proportion of inaccurate and incomplete data communicated during rounds between the 2 data collection periods. The Mann-Whitney $U$ test was used to determine differences in the timeliness of electronic medical record order entry and time to order completion. RESULTS: A 94.8\% survey response rate $(n=55)$ was obtained. Seventy-six percent of participants reported improved communication. Sixty-nine percent of participants reported improved teamwork. Eighty-six percent of orders were implemented immediately after electronic medical record entry. Correct information was provided on $95 \%$ and $99.3 \%$ of patients $(P<.066)$ and complete information on $93 \%$ and $96 \%$ of patients $(P=.41)$. CONCLUSIONS: Implementation of respiratory rounds improved staff satisfaction and the timeliness of completing respiratory orders. Spot monitoring at intermittent intervals verified process sustainability. Key words: interdisciplinary rounds; teamwork; outcome measures; organizational efficiency; neonatal; quality improvement; professionalism. [Respir Care 2015;60(3):321-327. (C) 2015 Daedalus Enterprises]
\end{abstract}

\section{Introduction}

Successful management of hospitalized patients with complex medical needs requires effective team participation and collaboration. Interdisciplinary rounding is a

\footnotetext{
Ms Genet and Ms Volsko are affiliated with the Department of Respiratory Care, and Ms Firestone is affiliated with the Neonatal Intensive Care Unit, Akron Children's Hospital, Akron, Ohio.

Ms Genet has disclosed no conflicts of interest. Ms Firestone has disclosed a relationship with Maquet. Ms Volsko has disclosed relationships with Sage Publications and Smiths Medical.
}

mechanism that is frequently used to establish and communicate patient care goals and review progress toward the accomplishment of set goals. The literature reports that

\footnotetext{
Ms Genet presented a version of this paper at the OPEN FORUM of the AARC Congress 2013, held November 16-19, 2013, in Anaheim, California.

Correspondence: Irene C Genet RRT, Department of Respiratory Care, Akron Children's Hospital, One Perkins Square, Akron, OH 44308. E-mail: irenegenet@sbcglobal.net.
}

DOI: $10.4187 /$ respcare.03489 
interdisciplinary rounds effectively establish and maintain teamwork, ${ }^{1,2}$ improve patient ${ }^{3,4}$ and financial ${ }^{5}$ outcomes, and increase job satisfaction. ${ }^{6}$

\section{See the Related Editorial on Page 471}

The rounding process, especially in academic medical centers, can be very time-intensive. This forum not only reviews and addresses the global care plan, but provides a venue to educate the clinical team. An effective rounding team requires a vested interest by the facilitator and participants and a commitment to the time it takes to execute this process. ${ }^{7}$

The literature reports that formal opportunities for shared decision making and forums that foster communication and collaboration between nurses and their medical colleagues are mutually beneficial. ${ }^{8}$ Studies have demonstrated that effective physician-nurse collaboration improves staff satisfaction and patient health outcomes through shared patient management decisions. ${ }^{8,9}$ However, there is a little information available with respect to job satisfaction, process efficiency, or patient outcomes when collaboration and responsibility for patient management are extended to all members of the interdisciplinary team.

An unintentional complication of the rounding process may be delays in care. Typically, orders are entered into the electronic medical records and carried out after rounds are completed. There is the potential, especially with high patient acuity and/or census, for this process to become very lengthy, which may impede the timely execution of ordered therapies. This may contribute to delays in initiating therapeutic modalities, such as airway clearance therapy, ventilator weaning trials, or extubating patients. A dearth of literature exists with respect to alternatives to formal interdisciplinary rounds, especially in the neonatal ICU (NICU).

An abbreviated process for addressing the plan of care for patients with respiratory care needs in the NICU, specifically respiratory therapist (RT)-led rounds, conducted before interdisciplinary rounds may provide a viable alternative to address process delays.

The aim of this study was to evaluate the effect RT-led rounds had on the timeliness of care plan orders, staff engagement, and staff job satisfaction in the NICU. We hypothesized that (1) staff satisfaction would improve with the implementation of RT-led rounds, (2) orders would be executed within $30 \mathrm{~min}$ of order entry into the electronic medical records, and (3) accurate and complete data would be communicated during rounds to the interdisciplinary team.

\section{QUICK LOOK}

\section{Current knowledge}

Multidisciplinary care of the critically ill patient represents the current standard of care in intensive care. Multidisciplinary rounds are frequently used to establish and communicate patient care goals and review progress.

\section{What this paper contributes to our knowledge}

In a single-center study using retrospective record review, implementation of patient rounds led by a respiratory therapist improved staff satisfaction and the timeliness of completing respiratory orders.

\section{Methods}

This single-institution study was approved by the institutional review board. The study was conducted in a 59bed Level 3C NICU with an average daily patient census of $52 ; \sim 60 \%$ of patients require some form of respiratory support. RT assignments are based on respiratory volume units and calculated twice daily, before the beginning of each 12-h shift. Typically, there is an average of 3 RTs assigned to the NICU. RT-led rounds, an abbreviated form of multidisciplinary rounds, provided a formal venue for the RTs assigned to the NICU to review the clinical presentation of each patient and address the global plan of care and patient progress along with the plan of care to the attending neonatologist, resident physicians, and advanced practice and bedside nurses. RT-led rounds were conducted each morning shortly after the beginning of the day or 7:00 Am shift. Multidisciplinary rounds were still conducted later in the morning. RT participation in multidisciplinary rounds occurred when changes in or discussion of the patient's response to the therapeutic plan of care were needed.

\section{Development of the Rounding Process}

Before the initiation of RT-led rounds, a reporting tool was developed to facilitate a uniform process for presenting clinical information to the interdisciplinary team. A core team of RTs and neonatologists developed and refined a tool that scripted the process for reporting patients' demographic information, such as gestational age, gender, and birth history, in addition to endotracheal tube size and placement; set, calculated, and measured ventilator parameters; and relevant laboratory results. This tool also included an area to identify the 24-h plan of care and global patient care plan and document patient progress with achiev- 
ing plan goals. The rounding tool and script for presenting a patient during respiratory rounds were piloted and refined with a larger group of RTs before implementation.

A brief educational session was conducted to introduce the RTs to the concept of the rounding process and use of the rounding tool. A 2-week pilot of the process was conducted after the educational session. The pilot provided an opportunity for the team to adjust to the new process and refine their workflow.

Of the 3 RTs assigned to the NICU, 2 attended RT-led rounds. One RT had the role of presenter, whereas the second RT had the role of transcriber. The RT presenting during the RT-led rounds used the reporting tool that was updated from shift-to-shift with all the pertinent information that occurred during the previous $12 \mathrm{~h}$. The second RT had the role of transcriber, carrying out orders at the bedside and documenting the changes in the electronic medical records along with updating the reporting tool. Extensive orders, such as extubation and modality changes, were carried out after the RT-led rounds were completed. It was the responsibility of the RT assigned to the NICU to carry out the 24-h plan and maintain the global plan for each patient.

\section{Staff Engagement/Satisfaction Assessment}

Six months after implementation of the RT-led rounds, a survey was conducted to evaluate the interdisciplinary team's engagement with this process. The survey tool was composed of 13 closed-ended questions that elicited demographic information, perceptions on engagement during RT-led rounds, and job satisfaction. Three demographic questions were used to ascertain the participant's role in the NICU, education, and work experience in the field of neonatal medicine. The remaining 10 questions were used to evaluate the participant's level of engagement with the rounding process and job satisfaction. The survey tool is provided in Figure 1.

The principle investigator kept track of staff who were recruited for and/or consented to study participation. This minimized the propensity to repeatedly approach staff for recruitment purposes. The survey was confidential and did not contain any participant identifiers. Each completed survey was placed in a sealed envelope by the participant and returned to the principle investigator or co-investigator. The sealed envelopes were collected and stored in a secure area until the close of the study period. This method reduced the likelihood that a survey could be linked to a participant.

\section{Quality and Process Monitoring}

To evaluate the timeliness of respiratory orders entered into the electronic medical records and accuracy of infor- mation reported by the RT during rounds, data were collected from the team during the rounding process. The principle investigator and colleagues physically attended rounds and documented any occurrence when information was missing or incomplete. The principle investigator and colleagues were regular participants in rounds, and the probability that their presence would influence the outcome of rounding was minimal. To minimize influencing the outcome, the team was not informed that communication data were being collected during RT-led rounds.

Process outcome data were collected through a medical record review. Outcome variables included the time that verbal orders for intervention were discussed on rounds to order entry in the electronic medical records and the time orders were completed by the RT. As a balancing measure, the number of additional respiratory orders entered into the electronic medical records during multidisciplinary teaching rounds was collected.

Two data collection periods were established. All data were collected for $10 \mathrm{~d}$ over a 2 -week period. The initial data collection period was conducted 6 months after initiation of respiratory rounds, and the second data collection period was conducted 12 months after establishment of the RT-led rounding process.

\section{Analytical Plan}

Data were entered into Excel (Microsoft, Redmond, California). Frequencies and percentage were used to describe participants' responses to job satisfaction and engagement survey questions. Descriptive statistics were used to report the number of patients who were visited during daily rounds, the number and type of orders given during rounds, and the number of respiratory orders that were addressed in multidisciplinary teaching rounds rather than during RTled rounds. The chi-square test was used to determine differences in the proportion of inaccurate and incomplete data communicated during rounds between the 2 data collection periods. The Mann-Whitney $U$ test was used to determine differences in the time to order entry in the electronic medical records after discussion on rounds and the time to order completion after orders were entered into the electronic medical records.

\section{Results}

\section{Staff Engagement/Satisfaction Assessment}

A $94.8 \%$ survey response rate $(n=55)$ was obtained. Fifty-two percent $(n=29)$ of the responses were received from registered nurses, whereas $18.1 \%(n=10)$ were completed by RTs. The remaining responses were completed by attending physicians, medical residents, and neonatal nurse practitioners. Forty percent of the RTs and 
RT-Led Rounds, Staff Satisfaction, and Timeliness of Respiratory Interventions

For the following questions check the response that best applies. Check only 1 response per question.

1. What is your role in the NICU?

$$
\begin{aligned}
& \square \text { Licensed Practical Nurse } \\
& \square \text { Attending physician } \\
& \square \text { Neonatal Nurse Practitioner } \\
& \square \text { Registered Nurse } \\
& \text { Registered Respiratory Therapist } \\
& \square \text { RRT1 } \\
& \square \text { RRT2 } \\
& \square \text { Other Please specify }
\end{aligned}
$$

2. What is the highest academic degree you have completed?

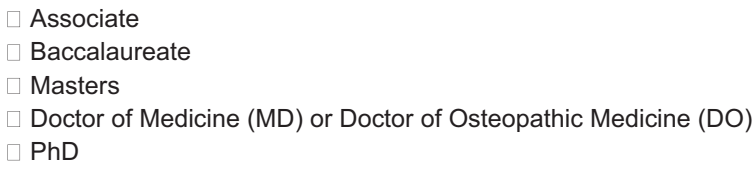

3. How many years of NICU experience have you completed?

$$
\begin{aligned}
& \square<5 \text { years } \\
& \square 6-9 \text { years } \\
& \square 10-14 \text { years } \\
& \square 15-19 \text { years } \\
& \square \geq 20 \text { years }
\end{aligned}
$$

Please provide your opinions regarding the respiratory rounds process. Please check SA for strongly agree, A for agree, $\mathrm{N}$ for neutral, $\mathrm{D}$ for disagree, and SD for strongly disagree.

4. Respiratory rounds have improved my understanding of the status of patients requiring respiratory support.
$\sqcap$ SA
$\square \mathrm{A}$
$\neg \mathrm{N}$
$\square \mathrm{D} \quad \square \mathrm{SD}$

5. Respiratory rounds have improved the communication among the interdisciplinary team members.
$\square \mathrm{SA}$
$\square \mathrm{A}$
$\square \mathrm{N}$
$\square \mathrm{D} \quad \square \mathrm{SD}$

6. Respiratory rounds have improved the timeliness of respiratory orders.
$\square \mathrm{SA}$
$\square \mathrm{A}$
$\square \mathrm{N}$
$\square \mathrm{D}$
$\square \mathrm{SD}$

7. The initiation of respiratory rounds has helped to create better time management.
$\square$ SA
$\square \mathrm{A}$
$\square \mathrm{N}$
$\square \mathrm{D}$
$\square \mathrm{SD}$

8. Respiratory rounds have improved staff morale.
$\square$ SA
$\square \mathrm{A}$
$\neg \mathrm{N}$
$\square \mathrm{D}$
$\square \mathrm{SD}$

9. Respiratory rounds have improved interdisciplinary teamwork.
$\square \mathrm{SA}$
$\square \mathrm{A}$
$\square \mathrm{N}$
$\square \mathrm{D}$
$\square \mathrm{SD}$

10. During respiratory rounds, the rounding team is supportive of the presentation and recommendations for care.
$\square \mathrm{SA}$
$\square \mathrm{A}$
$\square \mathrm{N}$
$\square \mathrm{D}$
$\square \mathrm{SD}$

Discipline Specific Questions:

Please skip to question 12 if you are a respiratory therapist.

11. Respiratory rounds have influenced the culture in the NICU toward the implementation of nurse-led rounds.
$\square$ SA
$\square \mathrm{A}$
$\square \mathrm{N}$
$\square \mathrm{D} \quad \square \mathrm{SD}$

Please answer question 12 if you are a respiratory therapist.

12. Since the implementation of respiratory rounds, I have more time for patient care.
$\square$ SA
$\square \mathrm{A}$
$\square \mathrm{N}$
$\square \mathrm{D}$
$\square \mathrm{SD}$

13. Respiratory rounds have improved my self-confidence.
$\square$ SA
$\square \mathrm{A}$
$\square \mathrm{N}$
$\square \mathrm{D}$
$\square$ SD

Thank-you for your participation in this survey. Please place this survey in the attached envelope, seal and deliver to

Fig. 1. Multidisciplinary survey tool used to measure staff satisfaction with the respiratory therapist-led rounding process. 
RT-Led Rounds, Staff Satisfaction, and Timeliness of Respiratory Interventions

Table 1. Interdisciplinary Team Engagement and Satisfaction Survey Results

\begin{tabular}{|c|c|c|c|c|c|c|}
\hline \multirow{2}{*}{$\begin{array}{c}\text { Survey } \\
\text { Instrument } \\
\text { Question No. }\end{array}$} & \multirow{2}{*}{$\begin{array}{c}\text { NICU Staff Perceptions Regarding RT-Led } \\
\text { Rounding Process }\end{array}$} & \multicolumn{5}{|c|}{ Likert Scale Responses Reported, $n(\%)$ of total } \\
\hline & & $\begin{array}{l}\text { Strongly } \\
\text { Agree }\end{array}$ & Agree & Neutral & Disagree & $\begin{array}{l}\text { Strongly } \\
\text { Disagree }\end{array}$ \\
\hline 4 & $\begin{array}{l}\text { Improved my understanding of the status of } \\
\text { patients requiring respiratory support }\end{array}$ & $3(5.5)$ & $28(50.9)$ & $19(34.5)$ & $4(7.3)$ & $1(1.8)$ \\
\hline 5 & $\begin{array}{l}\text { Improved communication among the } \\
\text { interdisciplinary team members }\end{array}$ & $12(21.8)$ & $30(54.5)$ & $10(18.2)$ & $3(5.5)$ & $0(0)$ \\
\hline 6 & $\begin{array}{l}\text { Improved the timeliness of completed respiratory } \\
\text { orders }\end{array}$ & $9(16.4)$ & $30(54.5)$ & $12(21.8)$ & $3(5.5)$ & $1(1.8)$ \\
\hline 7 & Helped to create better time management & $10(18.2)$ & $14(25.5)$ & $22(40)$ & $7(12.7)$ & $2(3.8)$ \\
\hline 8 & Improved staff morale & $1(1.8)$ & $11(20)$ & $31(35.4)$ & $6(10.9)$ & $1(1.8)$ \\
\hline 9 & Improved interdisciplinary teamwork & $11(20)$ & $27(49.1)$ & $14(25.5)$ & $2(3.6)$ & $1(1.8)$ \\
\hline 10 & $\begin{array}{l}\text { The rounding team is supportive of the RTs' } \\
\text { presentation and recommendations for care }\end{array}$ & $4(7.3)$ & $42(76.4)$ & $6(10.9)$ & $2(3.6)$ & $0(0)$ \\
\hline 11 & $\begin{array}{l}\text { Positively influenced the culture in the NICU } \\
\text { toward the implementation of nurse-led rounds }\end{array}$ & $2(3.6)$ & $19(34.5)$ & $19(34.5)$ & $4(7.3)$ & $0(0)$ \\
\hline 12 & RTs have more time for patient care & $1(1.8)$ & $2(3.6)$ & $4(7.3)$ & $2(3.6)$ & $1(1.8)$ \\
\hline 13 & Improved RTs' self-confidence & $0(0)$ & $5(9.1)$ & $4(7.3)$ & $0(0)$ & $2(3.6)$ \\
\hline
\end{tabular}

Question No. 11 was answered by all except the respiratory therapists (RTs). Questions No. 12 and No. 13 were only to be answered by the RTs. $\mathrm{NICU}=$ neonatal ICU

Table 2. Comparison of Process and Quality Outcomes From the Initial and Subsequent Data Collection Periods

\begin{tabular}{lcc}
\hline \hline & $\begin{array}{c}\text { First Data Collection Period } \\
(6 \text { mo after implementation })\end{array}$ & $\begin{array}{c}\text { Second Data Collection Period } \\
(12 \text { mo after implementation) }\end{array}$ \\
\hline Patients with data collected, $n(\%)$ & $135(100)$ & $133(100)$ \\
Patients with missing information noted on rounds, $n(\%)$ & $9(7)$ & $9(4)$ \\
Incorrect information communicated on RT-led rounds, $n(\%)$ & $7(5)$ & $1(0.8)$ \\
Time to execute orders entered into the electronic medical records, min & & .41 \\
Mean & 1.96 & .07 \\
Median & 1.0 & 0.29 \\
Range & $0-45$ & 0 \\
\pm SD & 5.7 & $0-10$ \\
Time to electronic medical record order entry, min & & 1.2 \\
Mean & 0.29 & .001 \\
Median & 0 & 0.29 \\
Range & $0-5.7$ & 0 \\
\pm SD & 0.93 & $0-5.4$ \\
\end{tabular}

0 min was used as the time stamp for order entry that was observed to occur immediately following communication of the plan of care. 0 min was used as the time stamp for orders that were implemented immediately after order entry in the electronic medical records.

$\mathrm{RT}=$ respiratory therapist

nurses were baccalaureate prepared $(n=22)$ and had $>20 \mathrm{y}$ of NICU experience $(n=22)$. The complete evaluation of the RT-led rounding process, perceptions of bedside care, and professional satisfaction results are provided in Table 1.

\section{Quality and Process Monitoring}

RTs reported on 135 patients during the first of 2 data collection periods, conducted approximately 6 months af- ter implementation of this process. Correct patient information was provided on $95 \%$ of patients, and complete information was provided on $93 \%$ of patients. Forty-seven percent of orders were immediately entered into the electronic medical records after there was consensus on the patient's plan of care (Table 2). Eighty-six percent of orders were immediately implemented when the orders were placed in the electronic medical records. There was one outlier in which an order was not carried out for $5 \mathrm{~h}$ and 
45 min after entry into the medical record. Four additional respiratory care orders were placed in the electronic medical records during multidisciplinary rounds, representing $5 \%$ of all respiratory care orders entered into the electronic medical records during the first data collection period.

RTs reported and data were recorded on 133 patients during the second data collection period $\sim 1$ y after implementation of this process. Correct patient information was provided on $99.3 \%$ of patients, and complete information was provided on $96 \%$ of patients. Eighty-four percent of orders were immediately entered into the electronic medical records after there was consensus on the patient's plan of care. Seventy-nine percent of orders were immediately executed after orders were entered into the electronic medical records (see Table 2). There were 8 additional respiratory care orders placed during multidisciplinary rounds, representing $11 \%$ of all respiratory orders entered during this second data collection period. There was no statistical difference in the time to enter orders or change in quality measures (missing and incomplete information communicated to the team by the RT during rounds) between the 2 data collection periods. However, there was a statistically significant improvement in the timeliness of order execution.

\section{Discussion}

RTs are integral members of the health-care team; however, few data are available to support their decision making role during interdisciplinary rounds. We sought to address this gap in the literature by describing staff satisfaction and process outcomes associated with RT-led rounds in the NICU. In concert with the nursing literature, those surveyed reported an improvement in interdisciplinary communication and teamwork. More than three quarters of those surveyed perceived that RT-led rounds improved communication among the interdisciplinary team members. More than half $(69 \%)$ of participants reported improvement in interdisciplinary teamwork. These findings are contrary to those of Thomas et $\mathrm{al}^{10}{ }^{10}$ who reported that perception discrepancies between the disciplines occurred. In a survey of 320 adult critical care physicians and nurses, $72 \%$ of whom were nurses, Thomas et $\mathrm{al}^{10}$ reported that $33 \%$ of nurses rated the quality of collaboration and communication with the physicians as high or very high, whereas $73 \%$ of physicians rated the quality of collaboration and communication with nurses as high or very high. Similar to the nursing literature, ${ }^{11}$ staff morale improved, and respiratory staff felt supported by bedside and advanced practice nurses and their physician colleagues.

The staff accurately perceived that this structured process improved the timeliness of orders. This was evidenced by the initial and sustained improvement in the entry and execution of respiratory care-related orders. There was a statistically significant decrease in the time in minutes to execute orders entered into the electronic medical records $(P<.001)$. Although the results did not reach statistical significance, from a quality perspective, the patient care information that the rounding team received during RT-led rounds became more accurate as the process matured. The workflow that the RTs developed for participation in RTled rounds to completing the orders for the patient plan of care was sustained for a 12-month period. This may be attributed to the participation in the development of this process by the bedside team. The process was created by the bedside practitioners and only facilitated by respiratory leadership, which may have enculturated a commitment to the process and commitment to a sustainable model. Therefore, as time progressed and the process became the standard of care, the RTs were aware of how important the communication of accurate and complete information was to the evaluation and determination of each patient's care plan.

\section{Conclusions}

The implementation of RT-led rounds improved staff satisfaction and the timeliness of completing respiratory orders. Spot assessments supported sustainability of the process and identified areas of improved efficiency. A limitation of this process included our inability to gather pre-implementation quality data. A measure of incorrect and/or incomplete information communicated by the RT before the implementation of RT-led rounds may have demonstrated the need to standardize the methods for and type of information provided to the rounding team. Additional effort focusing on the effects RT-led rounds may have on clinical outcomes, such as time to liberation from ventilation, use of noninvasive ventilation, length of time with oxygen, hospital stay, and chronic lung disease rate, will be the next step in the process improvement continuum.

\section{REFERENCES}

1. Weaver SJ, Lyons R, DiazGranados D, Rosen MA, Salas E, Oglesby $\mathrm{J}$, et al. The anatomy of health care team training and the state of practice: a critical review. Acad Med 2010;85(11):1746-1760.

2. O'Leary KJ, Wayne DB, Haviley C, Slade ME, Lee J, Williams MV. Improving teamwork: impact of structured interdisciplinary rounds on a medical teaching unit. J Gen Intern Med 2010;25(8):826-832.

3. O'Leary KJ, Sehgal NL, Terrell G, Williams MV, High Performance Teams and the Hospital of the Future Project Team. Interdisciplinary teamwork in hospitals: a review and practical recommendations for improvement. J Hosp Med 2012;7(1):48-54.

4. DuBose JJ, Inaba K, Shiflett A, Trankiem C, Teixeira PG, Salim A, et al. Measurable outcomes of quality improvement in the trauma intensive care unit: the impact of a daily quality rounding checklist. J Trauma 2008;64(1):22-27; discussion 27-29.

5. Dubose J, Teixeira PG, Inaba K, Lam L, Talving P, Putty B, et al. Measurable outcomes of quality improvement using a daily quality 
RT-Led Rounds, Staff SATisfaction, And Timeliness of Respiratory Interventions

rounds checklist: one-year analysis in a trauma intensive care unit with sustained ventilator-associated pneumonia reduction. J Trauma 2010;69(4):855-860.

6. O'Leary KJ, Haviley C, Slade ME, Shah HM, Lee J, Williams MV. Improving teamwork: impact of structured interdisciplinary rounds on a hospitalist unit. J Hosp Med 2011;6(2):88-93.

7. Ten Have EC, Hagedoorn M, Holman ND, Nap RE, Sanderman R, Tulleken JE. Assessing the quality of interdisciplinary rounds in the intensive care unit. J Crit Care 2013;28(4):476-482.
8. Rose L. Interprofessional collaboration in the ICU: how to define? Nurs Crit Care 2011;16(1):5-10.

9. Hughes B, Fitzpatrick JJ. Nurse-physician collaboration in an acute care community hospital. J Interprof Care 2010;24(6):625-632.

10. Thomas EJ, Sexton JB, Helmreich RL. Discrepant attitudes about teamwork among critical care nurses and physicians. Crit Care Med 2003;31(3):956-959

11. Rosenstein AH. Nurse-physician relationships: impact on nurse satisfaction and retention. Am J Nurs 2002;102(6):26-34.

This article is approved for Continuing Respiratory Care Education credit. For information and to obtain your CRCE

(free to AARC members) visit

www.rcjournal.com 